DOI: $10.5216 /$ cab.v13i4.14346

\title{
AVALIAÇÃO MORFOLÓGICA DO SISTEMA REPRODUTOR MASCULINO DE Panthera tigris
}

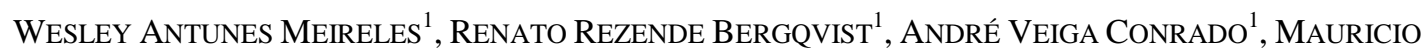 \\ DE Rosa TROTTA ${ }^{1}$, CARlos EduARdo AMBrósio ${ }^{2}$ \\ ${ }^{1}$ Pós-graduandos da Universidade de São Paulo, São Paulo, SP, Brasil - wesley.meireles@usp.br \\ ${ }^{2}$ Professor Doutor da Universidade de São Paulo, São Paulo, SP, Brasil
}

\section{RESUMO}

Os felinos silvestres compreendem um dos grupos sob grande risco de extinção. Este estudo descreveu a morfologia dos órgãos reprodutivos de um tigre (Panthera tigris) macho, adulto, cujo óbito ocorreu em procedimento cirúrgico. Fragmentos do escroto, testículos, epidídimos, ductos deferentes e pênis foram coletados para análise macroscópica e microscópica. Histologicamente, os órgãos reprodutivos foram semelhantes aos de outros felinos. Houve simetria testicular antimérica com o índice gonadossomático de $0,04 \%$, sendo os diâmetros dos túbulos seminíferos e ductos epididimários semelhantes ao descrito em felinos silvestres. A uretra peniana com diâmetro de $1,73 \mathrm{~mm}$ mostrou-se mais calibrosa. $\mathrm{O}$ pênis apresentou papilas cornificadas na glande, sendo as demais características anatômicas semelhantes a outras espécies felinas.

PALAVRAS-CHAVE: morfologia; felinos silvestres; sistema reprodutor masculino.

\section{MORPHOLOGICAL EVALUATION OF THE MALE REPRODUCTIVE SYSTEM OF TIGER (Panthera tigris)}

\section{ABSTRACT}

The wild felines comprise one of the animal groups under the greates risk of extinction. This case report aimed to describe the morphology of the reproductive organs of a male, adult tiger (Panthera tigris) that died during a surgical procedure. Fragments from scrotum, testis, epididymis, ductus deferens and penis were collected to macroscopic and microscopic analyses. Histologically, the reproductive organs were similar to other felines. The testis showed lateral asymmetry, with gonadosomatic index as 0.04, and the diameters presented by the seminiferous tubules and epididymal ducts were similar to those described for other species of wild felines. The penile urethra presented diameter of $1.73 \mathrm{~mm}$ and high caliber. The penis showed cornified papillae on the glans and other anatomical features described was similar to other felines.

KEYWORDS: anatomy; histology; male reproductive system; wild felines.

\section{INTRODUÇÃO}

As questões relacionadas à preservação dos ecossistemas representam importante pauta da atualidade (McGUIRE \& LACY, 1990). O avanço tecnológico e o crescimento demográfico da população mundial promoveram importantes alterações climáticas, mas também levaram a desconfigurações de biossistemas, ameaçando a vida de diversas espécies animais e vegetais (DONOGHUE et al., 1992). As modificações nos habitats, associadas à caça ilegal, provocaram a 
extinção de algumas espécies e ameaçam seriamente uma grande quantidade de espécies silvestres (JEWGEWOW et al., 2003). Felinos silvestres estão seriamente ameaçados de extinção, tanto no Brasil, quanto no restante do território global, fato que justificou este estudo de caso, além da comparação de dados da biologia reprodutiva entre felinos sulamericanos, que é um dos focos de nossas pesquisas atuais.

\section{MATERIAL E MÉTODOS}

Esta análise é descritiva e tratou de um estudo de caso de um exemplar de tigre (Panthera tigris) adulto, com doze anos de idade, e peso corporal de $200 \mathrm{~kg}$, proveniente do Zoológico de Sorocaba/SP, onde veio a óbito durante procedimento cirúrgico. Partes do cadáver foram aproveitadas na Faculdade de Medicina Veterinária e Zootecnia da Universidade de São Paulo para estudos morfológicos, tendo sido fixados (formalina $10 \%$ ), dissecados e documentados fotograficamente utilizando-se câmera digital Kodak P880 easyshare (Kodak $^{\circledR}$, Japão). A pesagem e medição dos órgãos foram realizadas com balança analítica digital e paquímetro digital (Western ${ }^{\text {en }}$ China). O índice gonadossomático foi calculado segundo a fórmula IGS $=$ peso testicular / peso corporal x 100, sendo o resultado expresso em porcentagem $(\%)$.

Fragmentos do testículo, epidídimo, funículo espermático, pênis e pele do escroto foram coletados e fixados em solução de formalina $10 \%$ durante 24 horas, desidratados em soluções de concentrações crescentes de etanol, diafanizados com xilol, incluídos em parafina. Em seguida foram seccionados em série com $5 \mu \mathrm{m}$ de espessura no micrótomo automático (Boeckeler Instruments ${ }^{\circledR}$, Estados Unidos). Foram preparadas quatro lâminas histológicas coradas com hematoxicilina/eosina. Imagens foram capturadas (Microscópio de luz Olympus BX3 acoplado à câmera AxioCam $\mathrm{HCr}$ com software de captura Axion Visio; Olympus ${ }^{\circledR}$, Japão) e analisadas (programa UTHSCSA-Image Tool versão 3.00 para Windows) para realização das mensurações dos diâmetros dos túbulos seminíferos, ductos epididimários e uretra, além da espessura do epitélio seminífero.

\section{RESULTADOS E DISCUSSÃO}

No exemplar de Panthera tigris foi feita análise morfológica de várias estruturas e aferidos valores biológicos e reprodutivos com fins de comparação a outras espécies descritas (DONOGHUE et al., 1990; SCUDAMORE \& MEREDITH, 2001). Na tabela 1 estão apresentados os parâmetros analisados.
Tabela 1: Parâmetros biológicos e reprodutivos de um tigre adulto (Panthera tigris). Faculdade de Medicina Veterinária e Zootecnia da Universidade de São Paulo, São Paulo (SP) 2010

\begin{tabular}{lc}
\hline Parâmetros & Valores \\
\hline Peso do animal $(\mathrm{kg})$ & 200 \\
Peso total do sistema reprodutor $(\mathrm{g})$ & 429 \\
Peso do testículo direito $(\mathrm{g})$ & 42 \\
Peso do testículo esquerdo $(\mathrm{g})$ & 39 \\
Comprimento do testículo direito $(\mathrm{cm})$ & 4,42 \\
Comprimento do testículo esquerdo $(\mathrm{cm})$ & 3,93 \\
Largura do testículo direito $(\mathrm{cm})$ & 3,84 \\
Largura do testículo esquerdo $(\mathrm{cm})$ & 3,67 \\
Peso total das gônadas $(\mathrm{g})$ & 81 \\
Índice gonadossomático $(\%)$ & 0,04 \\
Peso do epidídimo direito $(\mathrm{g})$ & 15 \\
Peso do epidídimo esquerdo $(\mathrm{g})$ & 12 \\
\hline
\end{tabular}

Os testículos apresentaram formato ovóide, sendo revestidos por uma túnica albugínea espessa (Figura 1A), com diferença de peso entre os antímeros (Tabela 1), corroborando a descrição de SCUDAMORE \& MEREDITH (2001) da morfometria testicular de um tigre em condições patológicas. A análise macroscópica detectou, na glande, papilas cornificadas (Figura 1B), semelhantes às dos gatos domésticos, cuja função é regulada por andrógenos para estimular a ovulação induzida nas fêmeas (DIAGONE, 2009). O pênis do tigre pode ser separado em base, corpo e glande, sendo que a base é composta por uma túnica albugínea peniana espessa (Figura 1C), como descrito em outros animais domésticos (DYCE et al., 2004). Nos cortes transversais do órgão, observouse a presença de osso peniano, na porção distal do corpo cavernoso, e também presença do corpo esponjoso e uretra peniana (Figura 1D).

O índice gonadossomático $(0,04 \%)$ encontrado foi maior do que nos Panthera leo $(0,015 \%)$, descrito por BARROS et al. (2006), e inferior em relação ao dos Felis catus $(0,08 \%)$, apontados por DIAGONE (2009), mas semelhante à Panthera onca $(0,05 \pm 0,01 \%)$ dos achados por COSTA et al. (2008).

Os pesos do epidídimo nos antímeros foram semelhantes aos encontrados em leões de cativeiro (BARROS et al., 2006).

$\mathrm{Na}$ histologia, o escroto é revestido por pele espessa, com epiderme queratinizada, derme rica em fibras de colágeno e glândulas sebáceas associadas aos folículos pilosos (Figura 1E). A túnica albugínea é espessa, principalmente na superfície dorsal dos testículos, formando o mediastino, de onde partem septos fibrosos que definem os lóbulos testiculares. O mediastino é a região onde está situada a rede testicular e parte dos túbulos retos, semelhante ao encontrado em gatos domésticos (FRANÇA \& GODINHO, 2003). O parênquima epitelial é formado pelos túbulos seminíferos no interior dos lóbulos, que estão arranjados de maneira enovelada. O epitélio seminífero, 
situado sobre a lâmina basal, é constituído de células de Sertoli e células da linhagem espermatogênicas, semelhante aos estudos com leões (BARROS et al., 2006) e onça pintada (COSTA et al., 2008). Os ductos eferentes do epidídimo estão localizados logo após o mediastino, ligando-se à rede testicular, forrados por células ciliadas com função de deslocar o espermatozóide no sentido do ducto epididimário (Figura 1F).

Os ductos epididimários são revestidos por epitélio pseudoestratificado prismático com estereocílios e presença de espermatozóides no lume conforme descrito em outros felídeos (DIAGONE, 2009). O ducto deferente possui túnica mucosa revestida por epitélio pseudoestratificado com microvilosidades, túnica muscular com camadas, circular interna, longitudinal externa e túnica adventícia rica em fibras elásticas, vasos e nervos. O lume do ducto deferente do tigre estava repleto de espermatozóides (Figura 1G). A glande do pênis esteve coberta por epitélio estratificado pavimentoso, destituído de glândulas, uretra peniana circundada pelo corpo esponjoso, enquanto o restante é envolto pelo corpo cavernoso (Figura $1 \mathrm{H}$ ).

Quanto à morfometria testicular, os valores de diâmetros tubulares encontrados no tigre indicaram resultados bem próximos aos de outros animais descritos (leões, 252,72 $\mu \mathrm{m}$; onça pintada $234 \mu \mathrm{m}$ e gato doméstico $220 \mu \mathrm{m}$ ) e pertencentes à família dos felídeos (FRANÇA \& GODINHO, 2003; BARROS et al., 2006; COSTA et al., 2008). Esses valores corroboram a análise feita neste exemplar.

A espessura detectada no epitélio seminífero (média de 77,19 $\mu \mathrm{m}$ ) foi inferior à de leões africanos $(93,2 \mu \mathrm{m})$ (BARROS et al., 2006) e gatos domésticos adultos $(81 \mu \mathrm{m})$ (FRANÇA \& GODINHO, 2003), aproximando-se ao valor encontrado na onça pintada $(77 \mu \mathrm{m})($ COSTA et al., 2008).

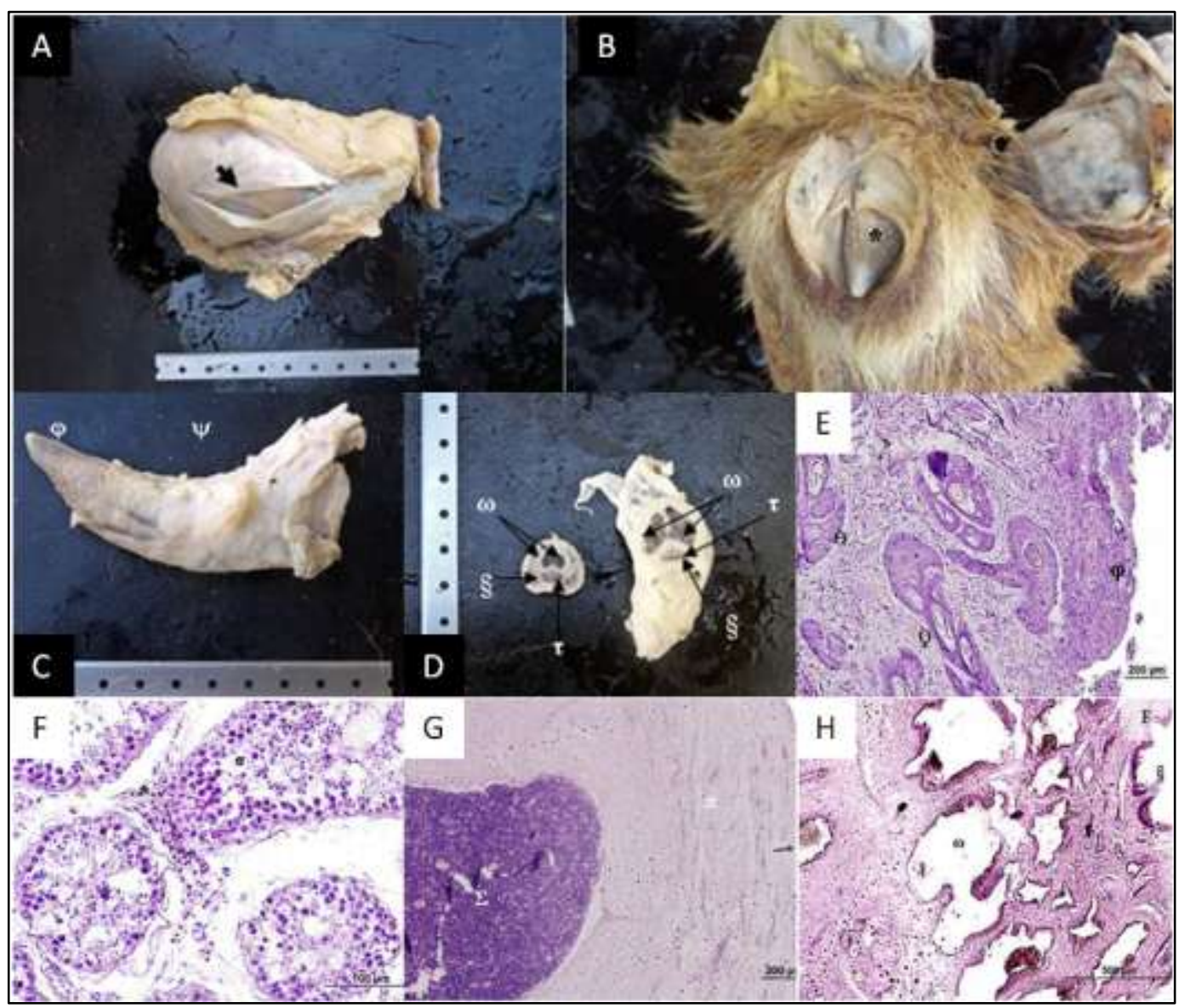

Figura 1: Fotografias de parte do sistema reprodutor masculino, com escroto revestido com pele pilosa; (A) testículo revestido por túnicas albugíneas espessas (seta); (B) glande do pênis contendo papilas queratinizadas [*]; (C) detalhe do pênis mostrando a glande $(\varphi)$ e corpo do pênis contendo a albugínea peniana $(\psi)$; (D) corte transversal do pênis mostrando corpos cavernosos $(\omega)$ e esponjoso $(\tau)$ e uretra $(\S)$ peniana. Comprimento da lâmina $=8 \mathrm{~cm}$. Fotomicrografias da pele do escroto mostrando epiderme queratinizada $[\varphi]$, glândulas sebáceas $[\Theta]$ associadas aos folículos pilosos $[Q]$; $(\mathrm{E})$, e detalhes das células germinativas nos túbulos seminíferos $[\sigma]$ e células do estroma intersticial $\left[{ }^{*}\right]$ em $(F) ;(G)$ ducto deferente com lume repleto de espermatozóides $[\Sigma]$ e túnica muscular $[\pi] ;(\mathrm{H})$ glande do pênis com presença de corpos cavernosos $(\omega)$, esponjosos $(\tau)$ e uretra peniana $(\S)$. 


\section{REFERÊNCIAS}

BARROS, J. B. G.; PAULA, TAR; MATTA, S. L. P.; FONSECA, C. C.; MELO, F. R.; BENJAMIM, L. A. Morfologia testicular e dos túbulos seminíferos de leõesafricanos (Panthera leo, Linnaeus, 1758) adultos, em cativeiro. Ceres, v. 53, p. 523-530, 2006.

COSTA, G. M. J.; CHIARINI-GARCIA, H.; MORATO, R. G.; ALVARENGA, R. L. L. S.; FRANÇA, L. R. Duration of spermatogenesis and daily sperm production in the jaguar (Panthera onca). Theriogenology, v. 70, p. 1136-1146, 2008.

DIAGONE, K. V. Histologia e morfometria dos testículos de gatos domésticos adultos. 2009. Tese (Doutorado) - Curso de Pós-graduação em Cirurgia Veterinária, da FCAV - UNESP, Jaboticabal, SP, 2009.

McGUIRE, L. A.; LACY, R. Allocating scarce resources for conservation of endangered subspecies : Partitioning zoo space for tigers. Conservation Biology, v. 4, p. 157166,1990

DONOGHUE, A. M; JOHNSTON, L. A.; SEAL, U. S.;
ARMSTRONG, D. L.; SIMMONS, L. G.; GROSS, T.; TILSON, R. L.; WILDT, D. E. Ability of thawed tiger (Panthera tigris) spermatozoa to fertilize conspecific eggs and bind and penetrate domestic cat eggs in vitro. Journal of Reproduction and Fertilization, v. 96, p. 555-564, 1992.

DYCE, K. M.; SACK, W. O.; WENSING, C. J. G. Tratado de anatomia veterinária. 3. ed. Rio de Janeiro: Elsevier, 2004.

FRANÇA, L. R.; GODINHO, C. L. Testis morphometry, seminiferous epithelium cycle length, and daily sperm production in domestic cats (Felis catus). Biology of Reproduction, v. 68, p. 1554-1561, 2003.

JEWGENOW, K.; HILDEBRANDT, T. B.; BLOTNER, S.; DEHNHARD, M.; HERMES, R.; RUDOLPH, M.; GORITZ, F. Reproductive disorders in male felids determined by ultrasonography, electroejaculation and hormone assessment. Verhandlungen Bericht Berlin Erkrankungen der Zootiere, v. 124, p. 79-82, 2001.

SCUDAMORE, CL; MEREDITH, AL. Sertoli cell tumour in an amur tiger. Journal of Comparative Pathology, v. 124, p. 79-82, 2001.

Protocolado em: 13 maio 2011. Aceito em: 04 dez. 2012. 